УДК 796 :37.012.6

https://doi.org/10.36906/FKS-2021/85

Рокосовская Л.Г.

Спортивная школа «Лесохимик», 2. Усть-Илимск, Россия

\title{
ПРОФИЛАКТИКА НАРУШЕНИЙ ОПОРНО-ДВИГАТЕЛЬНОГО АППАРАТА У ДЕТЕЙ ДОШКОЛЬНОГО И МЛАДШЕГО ШКОЛЬНОГО ВОЗРАСТА
}

Аннотация. Основа жизни человека это движение. Условия современного мира, предоставившие нам возможность меньше двигаться, а больше находиться в сидячем положении неблагоприятно влияют на нашу осанку.

Ключевые слова. Адаптивная физическая культура, осанка, плоскостопие, плавание, физические, корригирующие упражнения, нарушения опорно-двигательного аппарата.

Rokosovskaya L.G. Sports school "Lesohimik"

Ust-Ilimsk, Russia

\section{PREVENTION OF DISORDERS OF THE MUSCLE-MOTOR EQUIPMENT IN CHILDREN OF PRESCHOOL AND YOUNGER SCHOOL AGE}

Annotation. The basis of human life is movement. The conditions of the modern world, which provided us with the opportunity to move less and to be more in a sitting position, adversely affect our posture.

Keywords. Adaptive physical culture, posture, flat feet, swimming, physical, corrective exercises, disorders of the musculoskeletal system.

Адаптивная физическая культура - область общей физической культуры. Главная цель адаптивной физической культуры - максимальное развитие жизнеспособности человека. Долгое сидение перед компьютером в одной позе, постоянное ограничение физической активности, неравномерное распределение нагрузки на спину приводит к ослаблению мышц спины и развитию сколиоза. Цель исследования - обоснование комплекса мероприятий адаптивной физической культуры в профилактике нарушений опорно-двигательного аппарата у детей дошкольного и младшего школьного возраста с использованием средств оздоровительного плавания. Объект исследования - процесс физического воспитания детей. Предмет исследования - средства и методы оздоровительного плавания. Задачи исследования:

Изучить состояние вопроса по данным литературных источников.

Выявить основные средства и методы лечебно-оздоровительного плавания для профилактики нарушений опорно-двигательного аппарата у детей дошкольного и младшего школьного возраста.

Занятия с детьми дошкольного и младшего школьного возраста могут проводиться с использованием различных средств и методов. Одним из таких средств является дозированное плавание, как разновидность физических упражнений.

Элементы плавания способом «брасс» являются эффективным средством предупреждения и нарушения осанки. Основное преимущество заключается в выполнении одновременных симметричных движений руками и ногами в воде, позволяющим сохранять 
выпрямленное положение, голова опущена лицом в воду. Скорость передвижения брассом не большая, что позволяет ребенку плыть бесшумно, хорошо просматривать пространство над водой, преодолевать большие расстояния. Рабочие движения ног в способе брасс создают большую силу тяги. Каждый цикл движений в этом способе состоит из одного движения рук, одного движения ног, одного вдоха и одного выдоха в воду.

Основные принципы в обучении элементам способом «брасс»:

- принции доступности, позволяющий использовать преемственность физических упражнений (от известного к неизвестному, от освоенного к неосвоенному), стимулирующий активность и двигательную деятельность ребенка;

- принцип сознательной активности, стимулирующий формирование устойчивого интереса ребенка, как к процессу обучения, так и к конкретной задаче на каждом занятии;

- принщип новизны, позволяющий найти для обучаемого те движения, то сочетание движений, тот способ, которые бы отвечали его способностям, его одарённости, а так же целенаправленно выполнять корригирующие упражнения в воде;

- принцип систематичности и постепенности, т.е. непрерывность, регулярность и планомерность процесса для формирования прочного навыка плавания;

- приниии учета возрастных и индивидуальных особенностей детей предполагает построение занятий в соответствии с возможностями занимающихся, особенностями их возраста, пола, с учётом развития физических качеств, функционального состояния;

- принщип комплексности предполагает использование элементов плавания с корригирующими упражнениями на суше и в воде для укрепления опорно-двигательного аппарата.

Выполнение упражнений, разнообразных игр в воде содействуют разностороннему физическому развитию, стимулируют деятельность нервной, сердечнососудистой и дыхательной систем, значительно расширяют возможности опорно-двигательного аппарата. Физические упражнения, игры в воде требуют от детей полной перестройки обычного дыхания, которое связано с циклом движений и выполняется в строго определённый момент.

Подражательные упражнения «Ребёнок отражает мир»

Цель: Развитие двигательных способностей через познание детьми подражательных упражнений животных, которые живут в воде. Задачи:

- получение первичных сведений о представителях водного мира;

- обучение упражнениям, развивающим и укрепляющим мышцы спины и живота;

- воспитание бережного отношения к предметам природы;

- формирование правильной осанки.

«Улитка»

Вытянув пальцы, садимся на колени, на полу или на длинной скамье. Предплечьями упираемся в пол. Локти касаются колен, кисть лежит на полу и на ней другая. Ладони и большие пальцы как щупальца направлены вверх. ПЕДАГОГ: «Я - улитка, я - спешу, к водоёму я скольжу». Ребенок, не спеша поочерёдно передвигает голень, толкая коленом предплечье, не отрывая их от пола.

\section{«Пингвин»}

Ноги на ширине плеч, локти прямых рук прижаты к пояснице. Кисти сомкнутыми прямыми пальцами отставлены в стороны. Переносим тяжесть тела с одной выпрямленной ноги на другую, приподнимая ненагруженную ногу и перемещая её чуть вперёд. Таким шагом двигаемся вперёд. Произносим «Пи - пи - пи - пи - пи - пи - ПИН.

ПИ - пи - пи - пи - пи - ПИНГВИН». 
«Чайка»

ПЕДАГОГ: «Птенцы проголодались. Чайки, чайки - своих птенцов выручайте». Дети не спеша перемещаются на носках, руками машут вверх - вниз, изгибая их в локтях и в запястьях. Кричат: «Я - ЧАЙЙЙЙКА. Я - ЧАЙЙЙЙКА. ПТЕНЦОВ ВЫРУЧАЙКА».

ПЕДАГОГ: «За рыбой - ныряй - ка». Дети приседают на носки и опираются на выпрямленные пальцы, сложенные один над другим как клюв. Встают и продолжают «полёт». «Осьминог»

ПЕДАГОГ: «Плывёт серый осьминог, большая голова и много...»

ДЕТИ: «...щупалец и ног». Дети распределяются по 4, садятся на пол, спиной к спине и берутся за руки под локти. Ноги полусогнуты. ПЕДАГОГ: «А вот плывёт кит-кашалот с плавниками и без...»- ДЕТИ: «...ног». Оставшиеся ложатся на живот для подражания киту.

ПЕДАГОГ: «Осьминог, осьминог, у тебя сколько щупалец-ног?»

По готовности произносят хором: «Я осьминог, одна голова и 8 щупалец-ног». Педагог дожидается, когда сцепятся и ответят все группы, и говорит: «Восьминогий осьминог, где же, где же он живёт?» ДЕТИ: «В море живёт, быстро плавает». На протяжении этого высказывания беспорядочно двигают ногами, не отрывая ступни от пола. ПЕДАГОГ: «Я - кит. Я плыву в глубину, осьминога найду. Присосался он ко дну». Дети выпрямляют ноги и прижимают к полу, спину удерживая прямой. Хором: «По сторонам вокруг смотрю, спинку прямой я держу». Через 5-7 секунд педагог говорит: «Кит-кашалот плывёт, у осьминога яйца заберёт. Поднимаем свои ноги, как щупальца осьминога». Дети поднимают ноги и двигают ими, подражая щупальцам осьминога. Встают ПООДИ-ночки.

ЗАДАЧИ: выполнять по правилам и слаженно. В самом начале освоения этой игры педагогу необходимо обучить детей правильному и безопасному усаживанию на пол. Сначала им необходимо сесть, а уже потом сцеплять руки, чтобы предотвратить жесткое приземление, которое возможно при опускании в сцепленном виде.

\section{«Моржи»}

ПЕДАГОГ: «У моржей большие плавники и очень длинные...» - ДЕТИ: «...клыки». Распределяются по двое: мальчик с мальчиком, девочка с девочкой. Встают напротив друг друга. ПЕДАГОГ: «Из воды моржи на льдину легли и присели на большие свои...» - ДЕТИ: «...плавники». Встают на колени и присаживаются на пятки. ПЕДАГОГ: «Моржи сильны, а клыки их...» ДЕТИ: «...остры». Прямые пальцы соединяют. Запястье прижимают к щекам, а прямые пальцы направляют вниз. ПЕДАГОГ: «Моржи на льдине друг друга встречают. Моржи друг с другом осторожно...» ДЕТИ: «...играют». «Моржи» сближаются. ПЕДАГОГ: «Своими клыками друг друга...»- ДЕТИ: «...не ранят». Пальцами рук осторожно касаются пальцев другого. Давят на щёки, прогибаются назад, выдвигая таз и грудь вперед, и глядя вверх, произносят: «Я - мооРРРж». Встают.

Овладение элементами техники плавания способом брасс будет способствовать у детей повышению уровня физического развития, двигательной подготовленности, предупреждению и коррекции имеющихся нарушений опорно-двигательного аппарата. Использование новых форм индивидуального подхода к каждому ребенку, нетрадиционные пути взаимодействия занимающихся и педагога в конечном итоге приведёт к целостности педагогического воздействия на растущий организм ребенка, выступающего как единая продуманная система организации оздоровления детского организма.

\section{Литература}

1. Адонина М.А., Заика О.А., Кутькова Т.С. Проблема профилактики нарушений опорно-двигательного аппарата у младших дошкольников и пути их решения // Педагогика и 
психология: теория и практика: Сборник статей Международной научно-практической конференции. 2020. С. 81-83.

2. Воротилкина И.М. Физкультурно-оздоровительная работа в дошкольном образовательном учреждении. М: НЦ ЭНАС, 2014. 230 с.

3. Гребова Л.П. Лечебная физическая культура при нарушениях опорно-двигательного аппарата у детей и детей. М.: Академия, 2006. 176 с.

4. Красикова И.С. Осанка: Плоскостопие. Профилактика и лечение. СПб.: Корона.Век, 2011. $176 \mathrm{c}$.

(С) Рокосовская Л.Г., 2021 